\title{
Molecular survey and characterization of a novel Anaplasma species closely related to Anaplasma capra in ticks, northwestern China
}

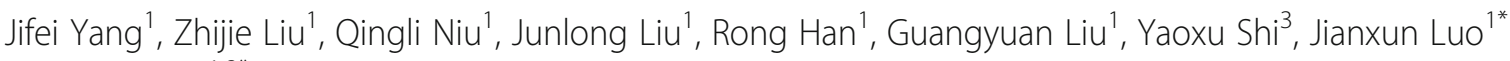 \\ and Hong Yin ${ }^{1,2^{*}}$
}

\begin{abstract}
Background: Anaplasma spp. are tick-transmitted bacteria that infect a wide variety of wild and domestic animals. These pathogens exhibit a high degree of biological diversity, broad geographical distribution, and represent a serious threat to veterinary and public health worldwide.

Results: A novel Anaplasma species was identified in Haemaphysalis qinghaiensis (Ixodidae) in northwestern China and was molecularly characterized by comparison of $16 \mathrm{~S}$ rRNA, gltA, and groEL gene sequences. Of the 414 samples tested, 24 (5.8\%) were positive for this Anaplasma species. On the basis of the $16 \mathrm{~S} \mathrm{rRNA} \mathrm{gene,} \mathrm{this} \mathrm{organism} \mathrm{has}$ been found to be closely related to and exhibit the highest sequence similarity with A. capra (99.8-99.9\%) that was identified in goats and humans in northern China, but was distinct from other known Anaplasma species. Sequence analysis of the gltA and groEL genes revealed that this Anaplasma species was distinct from A. capra considering the lower sequence identity (88.6-88.7\% for gltA and 90.6-91.0\% for groEL) and a divergent phylogenetic position. Therefore, we described this Anaplasma species as A. capra-like bacteria.
\end{abstract}

Conclusions: The present study reports a potential novel Anaplasma species closely related to A. capra in $H$. ginghaiensis in northwestern China. The zoonotic potential of A. capra-like bacteria needs to be further determined.

Keywords: Anaplasma, $16 \mathrm{~S}$ rRNA gene, gltA gene, groEL gene, Haemaphysalis qinghaiensis, A. capra-like bacteria, China

\section{Background}

Members of the genus Anaplasma are gram-negative obligate intracellular bacteria that reside within membraneenclosed vacuoles in the cytoplasm of blood or endothelial cells [1]. This genus encompasses seven recognized species, which are known to infect mammals and different cell types [1]. Anaplasma phagocytophilum infects neutrophils of animals and humans; Anaplasma marginale, Anaplasma centrale (A. marginale subsp. centrale), Anaplasma ovis and Anaplasma mesaeterum infect erythrocytes of ruminants;

\footnotetext{
* Correspondence: luojianxun@caas.cn; yinhong@caas.cn

'State Key Laboratory of Veterinary Etiological Biology, Key Laboratory of Veterinary Parasitology of Gansu Province, Lanzhou Veterinary Research Institute, Chinese Academy of Agricultural Science, Xujiaping 1, Lanzhou, Gansu 730046, People's Republic of China

Full list of author information is available at the end of the article
}

while Anaplasma bovis and Anaplasma platys infect bovine monocytes and canine platelets, respectively [2-4]. Recently, a novel Anaplasma species designated "Anaplasma capra" was identified in goats, ticks, and humans in northern China [5]. In addition to this species, other potential novel Anaplasma species or genetic variants have been reported on the basis of phylogenetic analysis of different gene loci in ticks and vertebrate hosts, particularly in wildlife, including Anaplasma odocoilei from white-tailed deer and "Candidatus Cryptoplasma californiense" from Ixodes pacificus in USA, A. platys-like strains from cats in Italy, and novel Anaplasma sp. from sika deer in Japan and dromedary camels in Saudi Arabia [6-10].

The discovery of novel tick-transmitted Anaplasma species indicates that the global burden of anaplasmosis on 
animal and human health has been underestimated. In general, several emerging tick-borne pathogens were initially identified in ticks or animals, but were identified as human pathogens much later. Anaplasma phagocytophilum was first described in 1932 in Scotland as the agent of tickborne fever in sheep [11]; however, the first case of human granulocytic anaplasmosis (HGA) was recorded in 1994 in the United States [12]. Anaplasma capra was initially found in goats, and human infection with this agent was subsequently reported in an active surveillance of patients in a hospital in northern China [5]. The novel identified Anaplasma species represent potential candidates for new tickborne diseases that have enriched our understanding of anaplasmosis. In the present study, a potential novel Anaplasma species closely related to A. capra was found in Haemaphysalis qinghaiensis ticks in a high altitude area in northwestern China.

\section{Methods}

Questing ticks were collected on the vegetation with the flagging method once a month between March and May 2011, in Gannan Tibetan Autonomous Prefecture (33 $06^{\prime \prime}-36^{\circ} 10^{\prime \prime N}, 100^{\circ} 46^{\prime \prime}-104^{\circ} 44^{\prime \prime E}$ ) in Gansu Province. The sampling sites were located in forest and pasturing areas that rely heavily on the farming of sheep, goats, and yaks for milk, and meat for the local economy. The average altitude at the sampling sites is over $3,000 \mathrm{~m}$. Ticks were identified as Haemaphysalis qinghaiensis microscopically on the basis of morphological parameters [13]. DNA was extracted from adult $H$. qinghaiensis ticks individually using the Puregene DNA purification kit (Qiagen, Beijing, China) according to the manufacturer's protocols.

The DNA of 414 tick samples was screened for the presence of the gltA gene of Anaplasma sp. by nested PCR, with the primers and PCR conditions described in Table 1. The first-round PCR was carried out with previously published primers [5]; the primers for the second-round amplification and the primers targeting 16S rRNA and groEL genes were designed based on the corresponding sequences of $A$. capra HLJ-14 using Primer Premier 5.0 software (PREMIER Biosoft International, 3786 Corina way, Palo Alto, CA, USA) [5]. In order to further identifying the agent, the partial 16S rRNA and the groEL gene fragments were amplified from samples positive for gltA gene of the Anaplasma sp. (Table 1). PCR reactions were performed in an automatic thermocycler (Bio-Rad, Hercules, USA). Genomic DNA extracted from infected ticks that had been verified by sequencing was used as the positive control, and sterile water was used as the negative control. PCR products were visualized by UV transillumination in a $1.0 \%$ agarose gel following electrophoresis and staining with ethidium bromide.

The PCR products of the gltA (594 bp), 16S rRNA (1,261 bp) and groEL (874 bp) genes were purified (TaKaRa Agarose Gel DNA purification Kit Ver. 2.0, Dalian, China), cloned (pGEM-T Easy vector, Promega, Madison, WI, USA) and subjected to sequencing using BigDye Terminator Mix (Sangon, Shanghai, China). The GenBank accession numbers of Anaplasma sp. detected in $H$. qinghaiensis ticks in this study are as follows (not including identical sequences): KX673824 and KX673825 (16S rRNA), KX685885 and KX685886 (gltA) and KX685887 and KX685888 (groEL). Sequences were compared with the published sequences in GenBank by a BLASTn search and analyzed with the Clustal W method in the MegAlign software (DNAStar, Madison, WI, USA). Phylogenetic analysis was conducted based on the sequence distance method using the neighbor-joining (NJ) algorithm with the Kimura two-parameter model of the Mega 4.0 Software [14]. The results were analyzed using a Chi-square test in Predictive for Analytics Software Statistics 18 (PASW, SPSS Inc., Chicago, IL, USA). P-values of 0.05 or less were considered statistically significant.

\section{Results and discussion}

In this study, DNA of an Anaplasma species was detected in H. qinghaiensis from Gannan Tibetan Autonomous Prefecture in Gansu Province, northwestern China. Haemaphysalis qinghaiensis is a distinctive tick species that is common in high altitude areas in northwestern China, and preferentially infests domestic animals such as sheep, goats, cattle and yaks $[13,15,16]$. Out of the $414 \mathrm{H}$. qinghaiensis

Table 1 Primers and PCR amplification conditions

\begin{tabular}{|c|c|c|c|c|c|}
\hline Target gene & Primer name & Primer sequence $\left(5^{\prime}-3^{\prime}\right)$ & Annealing temperature $\left({ }^{\circ} \mathrm{C}\right)$ & Amplicon size (bp) & Reference \\
\hline \multirow[t]{4}{*}{$g / t A$} & Outer-f & GCGATTTAGAGTGYGGAGATTG & 55 & 1,031 & {$[5]$} \\
\hline & Outer-r & TACAATACCGGAGTAAAAGTCAA & & & \\
\hline & Inner-f & TCATCTCCTGTTGCACGGTGCCC & 60 & 594 & This study \\
\hline & Inner-r & CTCTGAATGAACATGCCCACCCT & & & \\
\hline \multirow[t]{2}{*}{$16 \mathrm{~S}$ rRNA } & Forward & GCAAGTCGAACGGACCAAATCTGT & 58 & 1,261 & This study \\
\hline & Reverse & CCACGATTACTAGCGATTCCGACTTC & & & \\
\hline \multirow[t]{2}{*}{ groEL } & Forward & TGAAGAGCATCAAACCCGAAG & 55 & 874 & This study \\
\hline & Reverse & CTGCTCGTGATGCTATCGG & & & \\
\hline
\end{tabular}


ticks sampled, 24 (5.8\%) were positive for the Anaplasma sp. The infection rates of the Anaplasma sp. were comparable in female $(5.7 \%, 13 / 230)$ and male $(6.0 \%, 11 / 184)$ ticks $\left(\chi^{2}=0.02, P>0.05\right)$.

The Anaplasma sp. identified in $H$. qinghaiensis ticks was further characterized based on $16 \mathrm{~S}$ rRNA, gltA, and groEL genes. Sequence analysis showed that the $16 \mathrm{~S}$ rRNA gene sequences $(1,261 \mathrm{bp})$ were classified into two sequence types (ST), with $99.9 \%$ similarity, representing two different Anaplasma strains. Anaplasma sp. ST1 and ST2 (GenBank accession nos. KX673824 and KX673825) were 100\% identical to the strain NS104 and Kamoshika17 of unclassified Anaplasma species (GenBank accession nos. AB454075 and AB509223) that have been detected in deer and Capricornis crispus, respectively, in Japan. Furthermore, the $16 \mathrm{~S}$ rRNA gene sequences of these isolates were $99.8-99.9 \%$ identical (differed by one or two nucleotides) to strain HLJ14 of the emerging zoonotic A. capra (GenBank accession no. KM206273) that was reported in goats and humans in China [5]. Phylogenetic analyses based on 16S rRNA gene sequences revealed that the Anaplasma sp. ST1 and ST2 were in the same clade as members of Anaplasma (Fig. 1). These isolates were closely related to $A$. capra, but distinct from other known Anaplasma species (Fig. 1).

Further analyses of gltA and groEL gene sequences showed $98.8 \%$ and $98.0 \%$ similarity between the Anaplasma sp. ST1 and ST2, respectively. The gltA sequences of
Anaplasma sp. ST1 and ST2 (GenBank accession nos. KX685885 and KX685886) were 88.7\% and 88.6\% identical to A. capra (GenBank accession no. KM206274). The groEL sequences of Anaplasma sp. ST1 and ST2 (GenBank accession nos. KX685887 and KX685888) were 91.0\% and 90.6\% identical to A. capra (GenBank accession no. KM206275). Phylogenetic analysis based on gltA and groEL sequences showed that the Anaplasma sp. ST1 and ST2 clustered independently from A. capra and other Anaplasma species with high bootstrap values (Fig. 1), indicating potential novelty of the studied Anaplasma sp.

Ticks are important vectors of various pathogens that affecting domestic and wild animals as well as humans worldwide [17]. With the development of molecular tools, emerging tick-borne pathogens and the increasing number of tick-associated disease cases were identified in tropical and sub-tropical areas [18-20], suggesting that there are still new tick-borne pathogens to be discovered. In this study, an Anaplasma species was identified in $H$. qinghaiensis ticks in northwestern China. The Anaplasma sp. ST1 and ST2 were closely related to A. capra on the basis of $16 \mathrm{~S}$ rRNA gene (similarity of 99.8-99.9\%). However, sequence and phylogenetic analyses based on the gltA and groEL genes indicated that the Anaplasma sp. (ST1 and ST2) differed from A. capra considering the lower sequence identity and divergent phylogenetic position. According to the results presented here, we described the

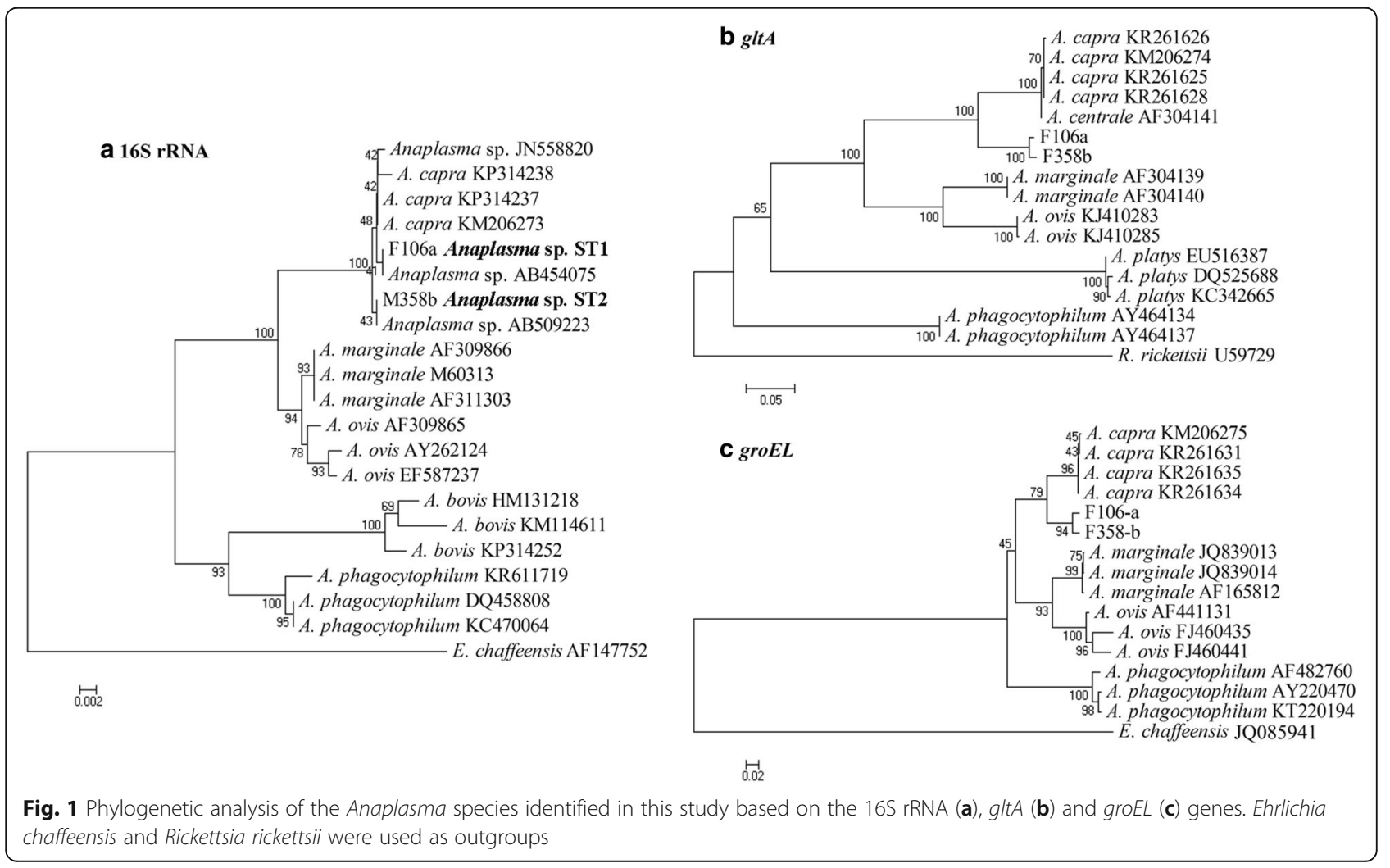


Anaplasma species identified from $H$. qinghaiensis ticks as A. capra-like bacteria.

The members of the genus Anaplasma are now recognized to be important human and animal pathogens [21]. To date, two Anaplasma species have been identified as pathogens of human anaplasmosis [5, 12]. Anaplasma phagocytophilum has been well studied and viewed as zoonotic pathogen for years already. Anaplasma capra was initially found in asymptomatic goats, and case of human infection were confirmed in 2015 in Heilongjiang province, northern China [5]. The agent was also detected in Ixodes persulcatus in Heilongjiang province and Haemaphysalis longicornis ticks in Shandong Province [22]. The illness caused by $A$. capra are different from $A$. phagocytophilum infection [5]. In this study, $A$. capra-like bacteria were identified in $H$. qinghaiensis ticks. However, it is still not clear whether this Anaplasma species is pathogenic to humans and animals.

The reservoir hosts of Anaplasma play a critical role in the maintenance of the pathogens in nature. As already mentioned, sequences that were identical to the A. capralike bacteria have been detected in deer (Anaplasma sp. NS104, GenBank accession no. AB454075) and in freeliving Capricornis crispus (Anaplasma sp. Kamoshika17, GenBank accession no. AB509223) in Japan [23]. Natural infections with these isolates in deer and Capricornis crispus suggested that the A. capra-like bacteria may be maintained in nature through enzootic cycles between ticks and wild animals. Several domestic and wild animal species as hosts of $H$. qinghaiensis ticks indicated that those animals could be reservoir hosts for the $A$. capra-like bacteria in study sites. The isolation of the organism from ticks and infected animals may help further elucidate the pathogenesis and characteristics of this Anaplasma species.

\section{Conclusions}

The present study reported a potential novel Anaplasma species closely related to A. capra in ticks in China. Twenty-four (5.8\%) of the $414 \mathrm{H}$. qinghaiensis ticks sampled were positive for the Anaplasma species. On the basis of the sequence and phylogenetic data, we described the Anaplasma species as $A$. capra-like bacteria.

\section{Abbreviations}

gltA: Citrate synthase; groEL: Heat-shock operon; ST: Sequence type

\section{Acknowledgements}

Not applicable.

\section{Funding}

This study was financially supported by the National Key Research and Development Program of China (2016YFC1202000, 2016YFC1202002); NSFC (31502091, 31402189, 31471967); ASTIP, FRIP (2014ZL010), CAAS; NBCIS CARS-38; 973 Program (2015CB150300); Jiangsu Co-innovation Center program for Prevention and Control of Important Animal Infectious Diseases and Zoonoses, State Key Laboratory of Veterinary Etiological Biology Project.
Availability of data and material

Sequences are submitted in the GenBank database under accession numbers KX673824-KX673825 and KX685885-KX685888

\section{Authors' contributions}

HY and JL designed this study and critically revised the manuscript. JY participated in its design, coordination and manuscript revision. JY, ZL, QN, $J \mathrm{~L}$ and $\mathrm{RH}$ participated in sample collection. JY, QN, RH, GL and YS performed the experiments, data analysis, drafted and revised the manuscript. All authors read and approved the final manuscript.

\section{Competing interests}

The authors declare that they have no competing interests.

\section{Consent for publication}

Not applicable.

\section{Ethics approval and consent to participate}

This study was approved by the Animal Ethics Committee of Lanzhou Veterinary Research Institute, Chinese Academy of Agricultural Sciences.

\section{Author details}

${ }^{1}$ State Key Laboratory of Veterinary Etiological Biology, Key Laboratory of Veterinary Parasitology of Gansu Province, Lanzhou Veterinary Research Institute, Chinese Academy of Agricultural Science, Xujiaping 1, Lanzhou, Gansu 730046, People's Republic of China. ${ }^{2}$ Jiangsu Co-innovation Center for Prevention and Control of Important Animal Infectious Diseases and Zoonoses, Yangzhou 225009, People's Republic of China. ${ }^{3}$ China Agricultural Veterinary Biological Sciences and Technology Co., Ltd, Lanzhou, Gansu 730046, People's Republic of China.

Received: 29 August 2016 Accepted: 11 November 2016

Published online: 25 November 2016

\section{References}

1. Dumler JS, Barbet AF, Bekker CP, Dasch GA, Palmer GH, Ray SC, et al. Reorganization of genera in the families Rickettsiaceae and Anaplasmataceae in the order Rickettsiales: unification of some species of Ehrlichia with Anaplasma, Cowdria with Ehrlichia and Ehrlichia with Neorickettsia, descriptions of six new species combinations and designation of Ehrlichia equi and 'HGE agent' as subjective synonyms of Ehrlichia phagocytophila. Int J Syst Evol Microbiol. 2001;51(Pt 6):2145-65.

2. Sreekumar C, Anandan R, Balasundaram S, Rajavelu G. Morphology and staining characteristics of Ehrlichia bovis. Comp Immunol Microbiol Infect Dis. 1996;19(1):79-83.

3. Rar V, Golovljova I. Anaplasma, Ehrlichia, and "Candidatus Neoehrlichia" bacteria: pathogenicity, biodiversity, and molecular genetic characteristics, a review. Infect Genet Evol. 2011;11(8):1842-61.

4. Uilenberg G, van Vorstenbosch CJ, Perie NM. Blood parasites of sheep in the Netherlands. I. Anaplasma mesaeterum sp.n. (Rickettsiales, Anaplasmataceae). Vet Quart. 1979:1(1):14-22.

5. Li H, Zheng YC, Ma L, Jia N, Jiang BG, Jiang RR, et al. Human infection with a novel tick-borne Anaplasma species in China: a surveillance study. Lancet Infect Dis. 2015;15(6):663-70.

6. Tate CM, Howerth EW, Mead DG, Dugan VG, Luttrell MP, Sahora Al, et al. Anaplasma odocoilei sp. nov. (family Anaplasmataceae) from white-tailed deer (Odocoileus virginianus). Ticks Tick Borne Dis. 2013;4(1-2):110-9.

7. Zobba R, Anfossi AG, Visco S, Sotgiu F, Dedola C, Pinna Parpaglia ML, et al. Cell tropism and molecular epidemiology of Anaplasma platys-like strains in cats. Ticks Tick Borne Dis. 2015;6(3):272-80.

8. Eshoo MW, Carolan HE, Massire C, Chou DM, Crowder CD, Rounds MA, et al. Survey of Ixodes pacificus Ticks in California Reveals a Diversity of Microorganisms and a Novel and Widespread Anaplasmataceae Species. PLoS One. 2015;10(9):e0135828.

9. Bastos AD, Mohammed OB, Bennett NC, Petevinos C, Alagaili AN. Molecular detection of novel Anaplasmataceae closely related to Anaplasma platys and Ehrlichia canis in the dromedary camel (Camelus dromedarius). Vet Microbiol. 2015;179(3-4):310-4.

10. Ybanez AP, Matsumoto K, Kishimoto T, Inokuma H. Molecular analyses of a potentially novel Anaplasma species closely related to Anaplasma 
phagocytophilum detected in sika deer (Cervus nippon yesoensis) in Japan. Vet Microbiol. 2012;157(1-2):232-6.

11. Woldehiwet Z. The natural history of Anaplasma phagocytophilum. Vet Parasitol. 2010;167(2-4):108-22.

12. Chen SM, Dumler JS, Bakken JS, Walker DH. Identification of a granulocytotropic Ehrlichia species as the etiologic agent of human disease. J Clin Microbiol. 1994;32(3):589-95.

13. Deng GF, Jiang ZL. Economic insect fauna of China, Fasc 39 Acari: Ixodiate. Beijing: Science Press; 1991.

14. Tamura K, Dudley J, Nei M, Kumar S. MEGA4: Molecular Evolutionary Genetics Analysis (MEGA) software version 4.0. Mol Biol Evol. 2007;24(8):1596-9.

15. Ma M, Guan G, Chen Z, Liu Z, Liu A, Gou H, et al. The life cycle of Haemaphysalis qinghaiensis (Acari: Ixodidae) ticks under laboratory conditions. Exp Appl Acarol. 2013:59(4):493-500.

16. Gao J, Luo J, Fan R, Fingerle V, Guan G, Liu Z, et al. Cloning and characterization of a cDNA clone encoding calreticulin from Haemaphysalis qinghaiensis (Acari: Ixodidae). Parasitol Res. 2008;102(4):737-46.

17. de la Fuente J, Estrada-Pena A, Venzal JM, Kocan KM, Sonenshine DE. Overview: Ticks as vectors of pathogens that cause disease in humans and animals. Front Biosci. 2008;13:6938-46.

18. Fang LQ, Liu K, Li XL, Liang S, Yang Y, Yao HW, et al. Emerging tick-borne infections in mainland China: an increasing public health threat. Lancet Infect Dis. 2015;15(12):1467-79.

19. Kuehn BM. Emerging tick-borne diseases expand range along with rebounding deer populations. JAMA. 2013;309(2):124-5.

20. Lin M, Kikuchi T, Brewer HM, Norbeck AD, Rikihisa Y. Global proteomic analysis of two tick-borne emerging zoonotic agents: anaplasma phagocytophilum and ehrlichia chaffeensis. Front Microbiol. 2011;2:24.

21. Kocan KM, de la Fuente J, Cabezas-Cruz A. The genus Anaplasma: new challenges after reclassification. Rev Sci Tech. 2015;34(2):577-86.

22. Sun XF, Zhao L, Wen HL, Luo LM, Yu XJ. Anaplasma species in China. Lancet Infect Dis. 2015;15(11):1263-4.

23. Sato M, Nishizawa I, Fujihara M, Nishimura T, Matsubara K, Harasawa R. Phylogenetic analysis of the 165 rRNA gene of Anaplasma species detected from Japanese serows (Capricornis crispus). J Vet Med Sci. 2009:71(12):1677-9.

\section{Submit your next manuscript to BioMed Central and we will help you at every step:}

- We accept pre-submission inquiries

- Our selector tool helps you to find the most relevant journal

- We provide round the clock customer support

- Convenient online submission

- Thorough peer review

- Inclusion in PubMed and all major indexing services

- Maximum visibility for your research

Submit your manuscript at www.biomedcentral.com/submit
Biomed Central 